\title{
Detection and differentiation of Cryptosporidium hominis and Cryptosporidium parvum by dual TaqMan assays
}

\begin{abstract}
Correspondence
N. Jothikumar

JIN2@cdc.gov
\end{abstract}

Received 26 February 2008

Accepted 14 May 2008

\author{
N. Jothikumar, ${ }^{1}$ A. J. da Silva, ${ }^{1}$ I. Moura, ${ }^{1,2}$ Y. Ovarnstrom ${ }^{1}$ and V. R. Hill ${ }^{1}$ \\ ${ }^{1}$ Centers for Disease Control and Prevention (CDC), National Center for Zoonotic, Vector-borne, \\ and Enteric Diseases, Division of Parasitic Diseases, Atlanta, GA 30341, USA \\ ${ }^{2}$ Atlanta Research and Education Foundation, Decatur, GA, USA
}

\begin{abstract}
Rapid identification of the two major species of Cryptosporidium associated with human infections, Cryptosporidium hominis and Cryptosporidium parvum, is important for investigating outbreaks of cryptosporidiosis. This study reports the development and validation of a real-time PCR TaqMan procedure for detection of Cryptosporidium species and identification of $C$. hominis and C. parvum in stool specimens. This procedure comprised a generic TaqMan assay targeting the 18S rRNA for sensitive detection of Cryptosporidium species, as well as two other TaqMan assays for identification of C. hominis and C. parvum. The generic Cryptosporidium species assay can be duplexed with the C. parvum-specific assay. The generic Cryptosporidium species assay was able to detect ten Cryptosporidium species and did not cross-react with a panel of ten other protozoan parasites. The generic Cryptosporidium species assay could detect 1-10 oocysts in a $300 \mu \mathrm{l} \mathrm{stool} \mathrm{specimen,} \mathrm{whilst} \mathrm{each} \mathrm{of} \mathrm{the} \mathrm{species-specific} \mathrm{TaqMan} \mathrm{assays} \mathrm{had}$ detection sensitivities that were approximately tenfold higher. The 18S rRNA assay was found to detect Cryptosporidium species in 49/55 DNA extracts from stool specimens containing either C. hominis or C. parvum. The C. hominis TaqMan assay correctly identified C. hominis in 24/31 validation panel specimens containing this species. The C. parvum-specific assay correctly identified C. parvum in 21/24 validation panel specimens containing this species. This real-time PCR procedure was used to detect and identify C. hominis and C. parvum in stool specimens from outbreak investigations in the USA and Botswana, resulting in identification of $C$. hominis and/or C. parvum in $66 / 67$ stool specimens shown to be positive for these species using other techniques. From the outbreak specimens tested, the TaqMan procedure was found to have a specificity of $94 \%$. This TaqMan PCR procedure should be a valuable tool for the laboratory diagnosis of cryptosporidiosis caused by C. hominis and C. parvum during outbreak investigations.
\end{abstract}

\section{INTRODUCTION}

Cryptosporidium is an important diarrhoea-causing parasitic protozoan found in both humans and animals (Fayer, 2004). The genus Cryptosporidium consists of at least 16 valid species, with two species, Cryptosporidium hominis and Cryptosporidium parvum, responsible for most cases of cryptosporidiosis in humans (Xiao et al., 2004). C. parvum is a zoonotic species, whereas $C$. hominis is anthroponotic. Other Cryptosporidium species that have been shown to cause illness in humans include Cryptosporidium meleagridis, Cryptosporidium felis and Cryptosporidium canis (Caccio \& Pozio, 2001; Gatei et al., 2002; Morgan et al., 2000; Pedraza-Diaz et al., 2000; Pieniazek et al., 1999; Xiao

Abbreviations: COWP, Cryptosporidium oocyst wall protein; DFA, direct fluorescent antibody. et al., 2001). Species discrimination is important for molecular epidemiological purposes to evaluate potential sources of infections. Conventional methods for detecting Cryptosporidium oocysts in faecal specimens involve microscopic detection of oocysts using either a direct fluorescent antibody (DFA) assay with broadly reactive Cryptosporidium species antibodies or a modified acid-fast staining technique. However, neither of these methods can identify Cryptosporidium at the species level, and their diagnostic strength depends on the skills of the examiner (Casemore et al., 1985; Pedraza-Diaz et al., 2000). An ELISA using mAbs against Cryptosporidium antigens has been developed and successfully used; however, this method cannot identify Cryptosporidium at the species level, despite being practical as a screening method (Graczyk et al., 1996). 
Molecular and biological differences were the basis for the classification of the C. parvum anthroponotic strain into a distinct species, $C$. hominis. The creation of this new taxon made it necessary to define the standards for specific molecular-based laboratory identification of the two most common Cryptosporidium species associated with diarrhoeal outbreaks worldwide. Various PCR formats have been employed to distinguish species of Cryptosporidium. PCR-based detection has been shown to be sensitive and specific for the detection of $C$. parvum in clinical specimens and environmental samples (Amar et al., 2001; Morgan et al., 1998; Sturbaum et al., 2001; Webster et al., 1996; Xiao et al., 2000). PCR-RFLP and PCR followed by DNA sequencing analysis have been described as reliable approaches for the distinction of $C$. hominis from $C$. parvum (formerly known as C. parvum genotypes 1 and 2, respectively) (McLauchlin et al., 2000; Pieniazek et al., 1999; Spano et al., 1997, 1998). Nevertheless, they are timeconsuming and labour-intensive, making them inadequate for a rapid diagnostic response during outbreak investigations.

Real-time PCR with specific primers and probes represents an alternative to conventional PCR for increasing the speed of sample analysis while decreasing the potential risks for contamination of the laboratory environment with amplicons. In the present study, we developed and validated a dual real-time PCR protocol in which a duplex TaqMan assay was used to detect Cryptosporidium species and $C$. parvum. A second TaqMan assay was used to detect $C$. hominis.

\section{METHODS}

Protozoan parasite and faecal specimens. $C$. hominis and $C$. parvum oocysts were obtained from human and bovine faecal specimens, respectively, by the method of Arrowood \& Donaldson (1996) and stored in $2.5 \%$ PBS at $4{ }^{\circ} \mathrm{C}$. The purified C. hominis and C. parvum stocks were determined to have concentrations of $2.2 \times 10^{7}$ and $33 \times 10^{7}$ oocysts $\mathrm{ml}^{-1}$, respectively, by counting oocysts on a haemocytometer. These stocks were used for specificity testing, as well as seeding of Cryptosporidium-negative stools to investigate the detection sensitivity of the molecular assays. The Cryptosporidium species identified in Table 1 were confirmed using a genotyping procedure based on the $18 \mathrm{~S}$ rRNA gene. In addition, analysis of the Cryptosporidium oocyst wall protein (COWP) gene (i.e. C- and Nterminal portions of the gene) was performed in the case of the $C$. parvum-like specimen obtained from lemurs (da Silva et al., 2003; Pieniazek et al., 1999; Spano et al., 1997; Xiao et al., 2001). All of the protozoan parasites identified in Table 1 as DNA specificity controls were analysed previously by the CDC Division of Parasitic Diseases reference diagnostics laboratory as part of different studies. They were confirmed by PCR using methods relying on sequencing analysis of a fragment of the 18S rRNA gene. The TaqMan assays developed for this study were validated using the panel of ten identified Cryptosporidium specimens reported in Table 1, as well as a blind panel consisting of 69 DNA extracts from human and animal stools, mussels and flies. This panel comprised 24 specimens known to be positive for C. parvum, 31 specimens known to be positive for $C$. hominis and 14 specimens known to contain non-Cryptosporidium protozoan parasites. The presence of $C$. hominis and $C$. parvum in
Table 1. Specificity testing results for genus- and specieslevel TaqMan assays

\begin{tabular}{|lccc|}
\hline Species tested & $\begin{array}{c}\text { 18S rRNA } \\
\text { assay }\end{array}$ & $\begin{array}{c}\text { C. hominis } \\
\text { assay }\end{array}$ & $\begin{array}{c}\text { C. parvum } \\
\text { assay }\end{array}$ \\
\hline C. hominis & + & + & - \\
C. parvum & + & - & + \\
C. canis & + & - & - \\
C. felis & + & - & - \\
C. parvum-like (from & + & - & - \\
lemur) & & & \\
C. muris & + & - & - \\
C. andersoni & + & - & - \\
C. baileyi & + & - & - \\
C. serpentis & + & - & - \\
C. wrairi & + & - & + \\
\hline
\end{tabular}

*da Silva et al. (2003).

these samples was confirmed by PCR amplification of the COWP and $18 \mathrm{~S}$ rRNA genes and of the microsatellite loci ML-1 and ML-2, followed by DNA sequencing analysis; the PCR primers and conditions used have been described previously (Caccio et al., 2000; Johnson et al., 1995; Spano et al., 1997, 1998; Xiao et al., 2001). DNA sequencing reactions were performed by cycle sequencing using BigDye version 3.1 chemistry (ABI). Sequencing data were obtained using an ABI Prism 3100 sequence analyser equipped with data collection software version 2.0 and DNA Sequence Analysis Software version 5.1. Sequences were assembled, edited and aligned in DNASTAR SeqMan, as well as in the GeneStudio suite. The validation panel was used to evaluate the ability of the real-time PCR protocol to correctly detect Cryptosporidium species and C. parvum or C. hominis (i.e. using the duplex TaqMan assay for Cryposporidium species and $C$. parvum, with a separate TaqMan assay for the detection of $C$. hominis). The validation panel was prepared by CDC staff not involved with the analysis of the specimens and was provided to CDC analytical staff as blind panels (i.e. with no descriptive identifiers).

Unpreserved stool specimens collected for epidemiological investigations of cryptosporidiosis in the USA and Botswana were shipped in chilled coolers from the study sites to CDC in Atlanta, USA. These stool specimens were refrigerated and tested using the DFA test and molecular assays [the real-time PCR assays of the present study, the ML-2 assay of Caccio et al. (2001) and the COWP assay of Spano et al. (1997)] within 1 week by the CDC laboratory staff.

DNA extraction. Total genomic DNA was extracted from 300-500 $\mu 1$ of stool sample spiked with Cryptosporidium oocysts and clinical samples using a modification of the FastDNA method (MP Biomedicals), as described previously (da Silva et al., 1999). Samples were disrupted in an FP120 cell disruptor (MP Biomedicals) at a speed of 5.5 for $10 \mathrm{~s}$. Potential inhibitors were removed by further purification using a QIAquick PCR purification kit (Qiagen) following the manufacturer's instructions. Purified DNA was stored at $4{ }^{\circ} \mathrm{C}$ until used in PCRs.

DFA assay. Microscopic examination of faecal specimens using the DFA assay was performed as a reference diagnostic technique that is commonly used in clinical laboratory practice. For microscopic examination, stool specimens were processed by ethyl acetate sedimentation (Ash \& Orihel, 1987). Direct wet smears prepared from each of the specimens in quadruplicate were air-dried and then processed separately with an acid-fast stain (Ash \& Orihel, 1987) and 
the DFA assay from the MeriFluor test kit (Meridian Diagnostic) (Nizeyi et al., 1999). Slides were examined for Cryptosporidium oocysts by light microscopy as described previously (Nizeyi et al., 1999).

\section{Primers and TaqMan probe design}

Cryptosporidium species TaqMan assay. The $18 \mathrm{~S}$ rRNA sequences for various species of Cryptosporidium were retrieved from GenBank. The alignments were performed using CLUSTAL_X (http://bips.ustrasbg.fr/en/Documentation/ClustalX/, version 1.81) and BioEdit sequence alignment software version 5.09 (http://www.mbio.ncsu.edu /BioEdit/bioedit.html). Consensus primers were designed after comparing several partial $18 \mathrm{~S}$ rRNA gene sequences for each Cryptosporidium species. The sequence of the forward primer (JVAF) was $5^{\prime}$-ATGACGGGTAACGGGGAAT-3', designed on $\mathrm{nt}$ 100-118 of GenBank accession number AY458612. The sequence of the reverse primer (JVAR) was 5'-CCAATTACAAAACCAAAAAGTCC-3', designed on nt 258-236 of GenBank accession number AY458612. The Cryptosporidium species TaqMan probe (JVAP18S), 5'-Cy5-CGCGCCTGCTGCCTTCCTTAGATG-BHQ-3', was designed based on nt 184-161 of GenBank accession number AY458612. This assay was designed to amplify all Cryptosporidium spp. for which $18 \mathrm{~S}$ DNA data were available. A BLAST analysis of GenBank indicated that the reverse primer would bind only when DNA from Cryptosporidium species was available as a template. GeneRunner version 3.05 (Hastings Software) was used to analyse the oligonucleotide primers and probes for the presence of secondary structure and to determine their thermal profiles. The final targeted sequences for the primers and probe were subjected to BLAST searches to ascertain their specificity for Cryptosporidium species sequences.

Species-specific TaqMan assays. A similar approach was used to design the primers and probes for the C. hominis- and C. parvumspecific TaqMan real-time PCR assays. These oligonucleotides were designed on the basis of GenBank accession number AF190627, which has been identified as being polymorphic, but with an undefined function (Widmer et al., 2000). The oligonucleotide sequences for the C. hominis TaqMan assay were: 5'-ACTTTTTGTTTGTTTTACGCCG-3' (JVAGF forward primer), 5'-AATGTGGTAGTTGCGGTTGAA-3' (JVAGR reverse primer) and 5'-FAM-ATTTATTAATTTATCTCTTACTTCGT-BHQ-3' (JVAGP1 probe). The oligonucleotide sequences for the C. parvum TaqMan assay were: $5^{\prime}$ ACTTTTTGTTTGTTTTACGCCG-3' (JVAGF forward primer), 5' AATGTGGTAGTTGCGGTTGAA-3' (JVAGR reverse primer) and 5' FAM-ATTTATCTCTTCGTAGCGGCG-BHQ-3' (JVAGP2 probe). The JVAGP2 probe, which was designed for specific detection of $C$. parvum, had a GC content of $48 \mathrm{~mol} \%$ and a $T_{\mathrm{m}}$ value of $63{ }^{\circ} \mathrm{C}$. For the C. parvum-specific probe (JVAGP2), a non-conventional design approach was needed in order to obtain a sufficient $T_{\mathrm{m}}$ for this GCpoor template. The $3^{\prime}$ end of the probe sequence $\left(5^{\prime}-\mathrm{CGGCG}-3^{\prime}\right)$ was made complementary to the $3^{\prime}$ end of the forward primer $\left(5^{\prime}\right.$ CGCCG- $3^{\prime}$ ) to raise its GC content. Because the forward primer had positive polarity and the probe was designed to have negative polarity, they should not compete for the same strand. The JVAGP1 probe had a GC content of $19 \mathrm{~mol} \%$ and a $T_{\mathrm{m}}$ value of $53{ }^{\circ} \mathrm{C}$ based on the nearest-neighbour method, but it was demonstrated in thermal gradient real-time PCR tests that the probe could hybridize effectively over a range of $45-60{ }^{\circ} \mathrm{C}$. All primers and probes reported in the present study were synthesized at the CDC Biotechnology Core Facility.

Real-time PCR conditions. Amplification of Cryptosporidium DNA was performed using an iCycler iQ4 Real-Time PCR Detection System (Bio-Rad) and an Mx 3000p system (Stratagene). For the duplex reaction (consisting of the $18 \mathrm{~S}$ rRNA assay and C. parvum assay), both TaqMan probes (JVAP18S and JVAGP2) were used at a final concentration of $100 \mathrm{nM}$ each and the four primers were used at a final concentration of $250 \mathrm{nM}$ each. For the separate C. hominis assay, the primers were used at the same concentration as in the duplex assay $(250 \mathrm{nM})$, but the concentration of the TaqMan probe (JVAGP1) was $200 \mathrm{nM}$ (twice the probe concentration used for the duplex assay). Additional $\mathrm{MgCl}_{2}$ was added to a final concentration of $5 \mathrm{mM}$ in the C. hominis assay reactions, to compensate for the low $T_{\mathrm{m}}$ of the probe. Real-time PCR amplifications were performed using the following conditions: denaturation at $95{ }^{\circ} \mathrm{C}$ for $2 \mathrm{~min}$, followed by 45 cycles of denaturation at $94{ }^{\circ} \mathrm{C}$ for $10 \mathrm{~s}$, annealing at $55{ }^{\circ} \mathrm{C}$ for $30 \mathrm{~s}$ and extension at $72{ }^{\circ} \mathrm{C}$ for $20 \mathrm{~s}$. Each $20 \mu \mathrm{l}$ reaction contained $10 \mu \mathrm{l}$ $2 \times$ Platinum Quantitative PCR SuperMix-UDG (Invitrogen), $5 \mu \mathrm{l}$ DNA, and primers, probe(s) and $\mathrm{MgCl}_{2}$ as described above.

Quantification and sensitivity analysis. The sensitivity of each TaqMan assay (18S rRNA, C. hominis-specific and C. parvumspecific) was determined using Cryptosporidium-negative stool specimens seeded with tenfold dilutions of either C. parvum or C. hominis from stocks quantified as described above. Quantitative PCR results were expressed as the number of Cryptosporidium oocysts per reaction. Standard curves were generated using DNA extracted from samples spiked with the equivalent of approximately $10^{5}-10^{-1}$ oocysts of each species. For the generation of standard curves, threshold cycle values were plotted proportionally to the logarithm of the input copy numbers. To assess the log-linear relationship of the assays, the linear regression coefficient $\left(R^{2}\right)$ was calculated by the iCycler iQ4 software for each assay. In addition, the sensitivity of the dual TaqMan assay protocol for detecting mixed infections was investigated by adding tenfold dilutions of DNA from the stock of $C$. parvum oocysts to DNA extracts from two clinical samples known to contain C. hominis. The effective range of C. parvum in these mixed DNA samples was from one to $10^{7}$ oocysts.

\section{RESULTS AND DISCUSSION}

\section{Specificity of the real-time PCR assays}

This study reports the development of a dual TaqMan assay procedure, consisting of a duplex assay targeting the $18 \mathrm{~S}$ rRNA gene for sensitive detection of Cryptosporidium species and a chromosomal gene of unknown function to identify C. parvum, combined with a singleplex TaqMan assay to identify $C$. hominis based on the same gene used for identification of C. parvum. The species-specific assays employed the same primers, but two distinct TaqMan probes were used. A panel of ten stool DNA extracts, each representing a different Cryptosporidium species, was tested to evaluate the detection scope of the generic 18S rRNA TaqMan assay and the specificity of the C. hominis and $C$. parvum TaqMan assays (evaluated as singleplex assays). The 18S rRNA assay was able to detect all ten Cryptosporidium species tested (Table 1). The C. parvum TaqMan assay was found to amplify only C. parvum and Cryptosporidium wrairi, which is rarely detected in the environment and is not known to infect humans (Xiao et al., 2004). The C. hominis TaqMan probe did not crossreact with any other species on the panel, including $C$. wrairi. The $18 \mathrm{~S}$ rRNA and species-specific TaqMan assays were found not to cross-react with ten DNA samples that contained protozoan parasites other than $C$. hominis and $C$. parvum (Table 2). 
Table 2. Validation testing results for Cryptosporidium species, C. hominis and C. parvum TaqMan PCR assays using a blind validation panel

\begin{tabular}{|lccccc|}
\hline Specimen & \multicolumn{4}{c|}{ No. of positive specimens/total no. of specimens tested (\%) } \\
\cline { 2 - 5 } & DFA assay & ML-2 assay & 18S rRNA assay & C. parvum assay & C. hominis assay \\
\hline C. hominis & $26 / 31(84)^{*}$ & $25 / 25(100)$ & $28 / 31(90)^{*}$ & $0 / 31$ & $24 / 31(77)$ \\
C. parvum & $21 / 23(91)^{*}$ & $19 / 20(95)$ & $21 / 24(88)^{*}$ & $21 / 24(88)$ & $0 / 24$ \\
Negative $\dagger$ & NA & NA & $0 / 14$ & $0 / 14$ & $0 / 14$ \\
\hline
\end{tabular}

NA, Not analysed.

${ }^{\star}$ For Cryptosporidium species.

$\dagger$ Negative for Cryptosporidium species. Stool specimens contained parasites other than Cryptosporidium as follows: Cyclospora cayetanensis ( $n=2$ isolates), Entamoeba histolytica $(n=1)$, Toxoplasma gondii $(n=1)$, Enterocytozoon bieneusi $(n=3)$, Entamoeba dispar $(n=1)$, Encephalitozoon cuniculi $(n=1)$, Giardia intestinalis $(n=1)$, Encephalitozoon hellem $(n=1)$, Entamoeba invadens $(n=1)$ and Encephalitozoon intestinalis $(n=2)$.

This is the first study to report the development of realtime PCR assays that can efficiently distinguish between $C$. hominis and C. parvum using TaqMan probes. Tanriverdi et al. (2002) reported a fluorescence resonance energy transfer (FRET) probe assay to distinguish between $C$. hominis and C. parvum, but the authors did not report sensitivity data and also indicated that the FRET probes did not perform well in resolving mixtures of $C$. hominis and $C$. parvum. Limor et al. (2002) also reported a FRET probe PCR assay that could discriminate between $C$. hominis and C. parvum, but the amplification efficiency of the assay was not sufficient to ensure sensitive detection of these two species. Tanriverdi et al. $(2002,2003)$ reported two different SYBR Green assays to distinguish between $C$. hominis and C. parvum based on melting curve analysis. Although effective in amplifying C. hominis and C. parvum DNA, these assays resulted in differentials of less than $0.5{ }^{\circ} \mathrm{C}$ in the melting peaks of the two species, which could limit their usefulness for definitive identification of $C$. hominis or C. parvum in clinical specimens. Nevertheless, comparative studies could be useful to ascertain the strength and weaknesses of the techniques mentioned above.

\section{Sensitivity of the TaqMan assays}

Standard curves developed using seeded stool specimens are shown in Fig. 1(a) for the 18S rRNA and C. hominis TaqMan assays and Fig. 1(b) for the 18S rRNA and $C$. parvum assays. The $R^{2}$ values for the standard curves were at least 0.99 for both assays over a quantification range of six orders of magnitude. The $18 \mathrm{~S}$ rRNA assay could detect 1-10 C. hominis and C. parvum oocysts seeded into $300 \mu \mathrm{l}$ stool specimens. Thus the lower limit of detection was 0.5 oocysts per reaction, which was a tenfold lower detection limit than the species-specific assays. This generic TaqMan assay targets the 18S rRNA gene, a multicopy gene (20 copies per oocyst) that offers a high degree of sensitivity. This level of sensitivity is similar to the detection limits reported by other researchers for detection of Cryptosporidium species, C. parvum or C. hominis
(Fontaine \& Guillot, 2002; Guy et al., 2003). As also shown in Fig. 1, the relative difference in the speed of detectable PCR product generation was $\sim 6$ threshold cycle values between the 18S rRNA and the species-specific assays. This difference in detection limits highlights an important design aspect of this TaqMan PCR procedure: a probe-based real-time PCR assay is used to target a gene present at high copy numbers for genus-level detection of Cryptosporidium species, whilst C. hominis and C. parvum identification is accomplished simultaneously by targeting
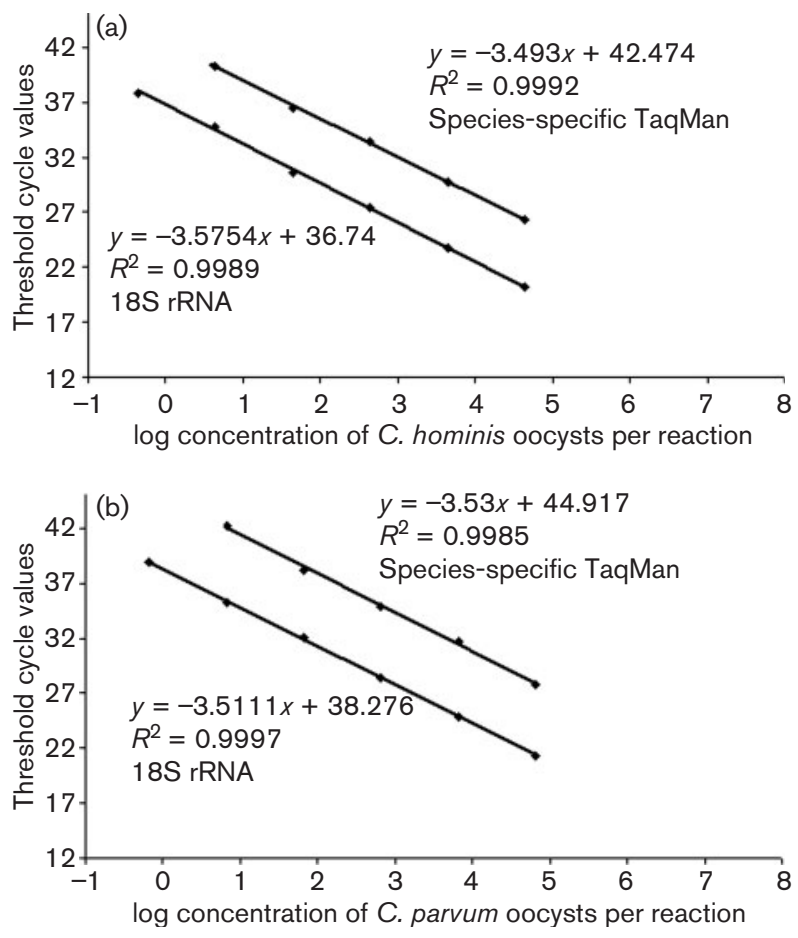

Fig. 1. Standard quantification curves for Cryptosporidium $18 \mathrm{~S}$ rRNA and species-specific TaqMan assays for C. hominis (a) and C. parvum (b). 
a different gene, present in lower copy numbers but having sufficient polymorphisms for species-level identification.

The sensitivity of the $C$. hominis and $C$. parvum assays for identifying a sample containing both species (as in an example of mixed infection) was also evaluated. Two $C$. hominis specimens containing approximately $10^{3}$ oocysts per reaction were mixed with tenfold dilutions of $C$. parvum oocysts. When the C. parvum oocyst addition was in the order of $10^{2}-10^{5}$ oocysts per reaction, the dual TaqMan assay protocol detected both $C$. hominis and $C$. parvum. When the $C$. parvum oocyst addition was in the order of $1-10$ oocysts or $10^{6}-10^{7}$ oocysts per reaction, the dual TaqMan assay protocol only detected the species that was more abundant in the mixed sample.

\section{Validation of the TaqMan assays versus reference molecular and microscopy methods}

Using a blind panel of 69 DNA extracts (containing 31 known $C$. hominis specimens, 24 known $C$. parvum specimens and 14 negative specimens), the $18 \mathrm{~S}$ rRNA and species-specific TaqMan assays were found to produce falsenegative (FN) rates that were similar to, or lower than, DFA microscopy and slightly higher than ML-2 PCR (Table 2). For the 31 known C. hominis specimens, the DFA and $18 \mathrm{~S}$ rRNA TaqMan assays detected Cryptosporidium species in 26 $(16 \% \mathrm{FN})$ and $28(10 \% \mathrm{FN})$ specimens, respectively. The $C$. hominis TaqMan assay correctly identified the presence of $C$. hominis in 24 of the 31 known $C$. hominis-positive specimens ( $23 \% \mathrm{FN})$. The C. parvum TaqMan probe did not cross-react with any of the $C$. hominis specimens. For the known C. parvum specimens, the DFA and 18S rRNA TaqMan assays detected Cryptosporidium species in 21/23 (9\% FN) and 21/24 (12\% FN) specimens, respectively. The C. parvum TaqMan assay correctly identified the presence of C. parvum in 21 of the 24 known C. parvum specimens (12\% FN). The C. hominis TaqMan probe did not crossreact with any of the $C$. parvum specimens.

\section{Use of dual TaqMan assay protocol for epidemiological investigation of cryptosporidiosis}

A total of 103 stool specimens from epidemiological investigations of cryptosporidiosis in the USA and Botswana were analysed by DFA microscopy, ML-2 PCR and our dual TaqMan PCR procedure to diagnose the presence of Cryptosporidium species. Cryptosporidium oocysts were observed in $51(49 \%)$ of the 103 specimens using DFA microscopy (Table 3). The $18 \mathrm{~S}$ rRNA TaqMan PCR assay detected the presence of Cryptosporidium species DNA in $67(65 \%)$ of the 103 specimens, whilst the ML-2 assay was able to detect Cryptosporidium in 61 (59\%) of the specimens. Cryptosporidium was detected in 71 of the 103 specimens using either the DFA or ML-2 assay, indicating that the TaqMan procedure had a specificity of $94 \%(67 /$ 71) for detecting Cryptosporidium in clinical specimens.
Table 3. Sensitivity of Cryptosporidium species detection using the DFA, ML-2 PCR and dual TaqMan PCR protocols for epidemiological investigations of cryptosporidiosis in the USA and Botswana

\begin{tabular}{|lcccc|}
\hline Specimen & \multicolumn{4}{c|}{ Analytical results for assay method } \\
\cline { 2 - 5 } & DFA & ML-2 & $\begin{array}{c}\text { 18S rRNA } \\
\text { assay }\end{array}$ & $\begin{array}{c}\text { All } \\
\text { assays }\end{array}$ \\
\hline $\begin{array}{l}\text { Cryptosporidium species } \\
\text { Negative } \dagger\end{array}$ & 51 & 61 & $67^{\star}$ & 71 \\
& 52 & 42 & 36 & 32 \\
\hline
\end{tabular}

${ }^{\star} C$. hominis $(n=35), C$. parvum $(n=29)$ or a mixture of $C$. hominis and $C$. parvum $(n=2)$ was identified in $66 / 67$ specimens using the species-specific TaqMan assays.

$\dagger$ Negative for Cryptosporidium species.

Three DFA-positive specimens were reported as Cryptosporidium-negative using the $18 \mathrm{~S}$ rRNA TaqMan and ML-2 assays, but were positive by other PCR and $18 \mathrm{~S}$ sequencing methods (data not shown). Nevertheless, the $18 \mathrm{~S}$ rRNA TaqMan assay was able to detect Cryptosporidium in 16 specimens that were reported as negative by DFA assay and in six specimens that were reported as negative using the ML-2 assay. Of the 67 specimens for which the TaqMan procedure detected Cryptosporidium species, C. hominis and/or C. parvum were detected in 66 specimens: 35 contained C. hominis, 29 contained C. parvum and two contained both $C$. hominis and C. parvum.

A total of 24 stool specimens from the Botswana set were subjected to DNA sequencing analysis after amplification with COWP N-terminal PCR primers CRY9 and CRY15 (Spano et al., 1997) to confirm the results obtained by the specific TaqMan assays. COWP-based sequencing analysis identified 12 specimens as containing $C$. hominis, 11 specimens as containing $C$. parvum and one specimen as coming from a case of mixed infection of $C$. hominis and $C$. parvum. The mixed infection was determined by sequencing analysis of cloned COWP N-terminal amplicons, as reported by Bandyopadhyay et al. (2007). The same identification results were achieved for the 24 stool specimens using our TaqMan procedure.

The results of the dual TaqMan assays for the stool specimens from the USA and Botswana showed that the real-time PCR procedure of the present study can provide accurate detection and identification of $C$. hominis and $C$. parvum in stool specimens collected for epidemiological studies. In addition to identifying $C$. hominis and $C$. parvum as the sole aetiological agents of cryptosporidiosis cases, the species-specific TaqMan assays also identified two cases of mixed infection, of which one was confirmed by COWP-based DNA sequencing analysis. The blindpanel validation of the dual TaqMan assay method showed that it has a detection sensitivity that is better than conventional microscopy and comparable to other 
molecular methods used for confirmatory identification of Cryptosporidium species. These data and capabilities indicate that this method could be a simple and valuable tool for fast and reliable laboratory diagnosis of $C$. hominis and C. parvum cryptosporidiosis.

\section{ACKNOWLEDGEMENTS}

The authors thank Dr Lihua Xiao (CDC) for providing Cryptosporidium specificity controls, Stephanie Johnston (CDC) for performing DFA analyses and Marcos de Almeida (CDC) for performing optimization evaluations of the real-time PCR assays. The authors also thank the following individuals who comprised the field team in Botswana that collected the stool specimens used for this study: Anna Bowen, Tracy Creek, Andrea Kim, Lydia Lu and Wences Arvelo (CDC); Japhter Masunge (Nyangabgwe Hospital, Francistown, Botswana); and Maruping Maruping, Gibson Ngwaru, Temana Johny and Vincent Nkwe [BOTUSA Project (CDC-Botswana)]. Use of trade names and commercial sources is for identification only and does not imply endorsement by the CDC or the US Department of Health and Human Services.

\section{REFERENCES}

Amar, C., Pedraza-Diaz, S. \& McLauchlin, J. (2001). Extraction and genotyping of Cryptosporidium parvum DNA from fecal smears on glass slides stained conventionally for direct microscope examination. J Clin Microbiol 39, 401-403.

Arrowood, M. J. \& Donaldson, K. (1996). Improved purification methods for calf-derived Cryptosporidium parvum oocysts using discontinuous sucrose and cesium chloride gradients. J Eukaryot Microbiol 43, 89S.

Ash, L. \& Orihel, T. (1987). Collection and preservation of feces. In Parasites: a Guide to Laboratory Procedures and Identification. Chicago: American Society of Clinical Pathologists.

Bandyopadhyay, K., Kellar, K. L., Moura, I., Cristina, M., Carollo, C., Graczyk, T. K., Slemenda, S., Johnston, S. P. \& da Silva, A. J. (2007). Rapid microsphere assay for identification of Cryptosporidium hominis and Cryptosporidium parvum in stool and environmental samples. J Clin Microbiol 45, 2835-2840.

Caccio, S. \& Pozio, E. (2001). Molecular identification of food-borne and water-borne protozoa. Southeast Asian J Trop Med Public Health 32 (Suppl. 2), 156-158.

Caccio, S., Homan, W., Camilli, R., Traldi, G., Kortbeek, T. \& Pozio, E. (2000). A microsatellite marker reveals population heterogeneity within human and animal genotypes of Cryptosporidium parvum. Parasitology 120, 237-244.

Caccio, S., Spano, F. \& Pozio, E. (2001). Large sequence variation at two microsatellite loci among zoonotic (genotype C) isolates of Cryptosporidium parvum. Int J Parasitol 31, 1082-1086.

Casemore, D. P., Armstrong, M. \& Sands, R. L. (1985). Laboratory diagnosis of cryptosporidiosis. J Clin Pathol 38, 1337-1341.

da Silva, A. J., Bornay-Llinares, F. J., Moura, I. N., Slemenda, S. B., Tuttle, J. L. \& Pieniazek, N. J. (1999). Fast and reliable extraction of protozoan parasite DNA from fecal specimens. Mol Diagn 4, 57-64.

da Silva, A. J., Caccio, S., Williams, C., Won, K. Y., Nace, E. K., Whittier, C., Pieniazek, N. J. \& Eberhard, M. L. (2003). Molecular and morphologic characterization of a Cryptosporidium genotype identified in lemurs. Vet Parasitol 111, 297-307.

Fayer, R. (2004). Cryptosporidium: a water-borne zoonotic parasite. Vet Parasitol 126, 37-56.
Fontaine, M. \& Guillot, E. (2002). Development of a TaqMan quantitative PCR assay specific for Cryptosporidium parvum. FEMS Microbiol Lett 214, 13-17.

Gatei, W., Ashford, R. W., Beeching, N. J., Kamwati, S. K., Greensill, J. \& Hart, C. A. (2002). Cryptosporidium muris infection in an HIVinfected adult, Kenya. Emerg Infect Dis 8, 204-206.

Graczyk, T. K., Cranfield, M. R. \& Fayer, R. (1996). Evaluation of commercial enzyme immunoassay (EIA) and immunofluorescent antibody (FA) test kits for detection of Cryptosporidium oocysts of species other than Cryptosporidium parvum. Am J Trop Med Hyg 54, 274-279.

Guy, R. A., Payment, P., Krull, U. J. \& Horgen, P. A. (2003). Real-time PCR for quantification of Giardia and Cryptosporidium in environmental water samples and sewage. Appl Environ Microbiol 69, $5178-5185$.

Johnson, D. W., Pieniazek, N. J., Griffin, D. W., Misener, L. \& Rose, J. B. (1995). Development of a PCR protocol for sensitive detection of Cryptosporidium oocysts in water samples. Appl Environ Microbiol 61, 3849-3855.

Limor, J. R., Lal, A. A. \& Xiao, L. (2002). Detection and differentiation of Cryptosporidium parasites that are pathogenic for humans by realtime PCR. J Clin Microbiol 40, 2335-2338.

McLauchlin, J., Amar, C., Pedraza-Diaz, S. \& Nichols, G. L. (2000). Molecular epidemiological analysis of Cryptosporidium spp. in the United Kingdom: results of genotyping Cryptosporidium spp. in 1,705 fecal samples from humans and 105 fecal samples from livestock animals. J Clin Microbiol 38, 3984-3990.

Morgan, U. M., Pallant, L., Dwyer, B. W., Forbes, D. A., Rich, G. \& Thompson, R. C. (1998). Comparison of PCR and microscopy for detection of Cryptosporidium parvum in human fecal specimens: clinical trial. J Clin Microbiol 36, 995-998.

Morgan, U., Weber, R., Xiao, L., Sulaiman, I., Thompson, R. C., Ndiritu, W., Lal, A., Moore, A. \& Deplazes, P. (2000). Molecular characterization of Cryptosporidium isolates obtained from human immunodeficiency virus-infected individuals living in Switzerland, Kenya, and the United States. J Clin Microbiol 38, 1180-1183.

Nizeyi, J. B., Mwebe, R., Nanteza, A., Cranfield, M. R., Kalema, G. R. \& Graczyk, T. K. (1999). Cryptosporidium sp. and Giardia sp. infections in mountain gorillas (Gorilla gorilla beringei) of the Bwindi Impenetrable National Park, Uganda. J Parasitol 85, 1084-1088.

Pedraza-Diaz, S., Amar, C. \& McLauchlin, J. (2000). The identification and characterisation of an unusual genotype of Cryptosporidium from human faeces as Cryptosporidium meleagridis. FEMS Microbiol Lett 189, 189-194.

Pieniazek, N. J., Bornay-Llinares, F. J., Slemenda, S. B., da Silva, A. J., Moura, I. N., Arrowood, M. J., Ditrich, O. \& Addiss, D. G. (1999). New Cryptosporidium genotypes in HIV-infected persons. Emerg Infect Dis 5, 444-449.

Spano, F., Putignani, L., McLauchlin, J., Casemore, D. P. \& Crisanti, A. (1997). PCR-RFLP analysis of the Cryptosporidium oocyst wall protein (COWP) gene discriminates between C. wrairi and C. parvum, and between C. parvum isolates of human and animal origin. FEMS Microbiol Lett 150, 209-217.

Spano, F., Putignani, L., Guida, S. \& Crisanti, A. (1998). Cryptosporidium parvum: PCR-RFLP analysis of the TRAP-C1 (thrombospondin-related adhesive protein of Cryptosporidium-1) gene discriminates between two alleles differentially associated with parasite isolates of animal and human origin. Exp Parasitol 90, 195-198.

Sturbaum, G. D., Reed, C., Hoover, P. J., Jost, B. H., Marshall, M. M. \& Sterling, C. R. (2001). Species-specific, nested PCR-restriction fragment length polymorphism detection of single Cryptosporidium parvum oocysts. Appl Environ Microbiol 67, 2665-2668. 
Tanriverdi, S., Tanyeli, A., Baslamisli, F., Koksal, F., Kilinc, Y., Feng, X., Batzer, G., Tzipori, S. \& Widmer, G. (2002). Detection and genotyping of oocysts of Cryptosporidium parvum by real-time PCR and melting curve analysis. J Clin Microbiol 40, 3237-3244.

Tanriverdi, S., Arslan, M. O., Akiyoshi, D. E., Tzipori, S. \& Widmer, G. (2003). Identification of genotypically mixed Cryptosporidium parvum populations in humans and calves. Mol Biochem Parasitol 130, 13-22.

Webster, K. A., Smith, H. V., Giles, M., Dawson, L. \& Robertson, L. J. (1996). Detection of Cryptosporidium parvum oocysts in faeces: comparison of conventional coproscopical methods and the polymerase chain reaction. Vet Parasitol 61, 5-13.

Widmer, G., Akiyoshi, D., Buckholt, M. A., Feng, X., Rich, S. M., Deary, K. M., Bowman, C. A., Xu, P., Wang, Y. \& other authors (2000).
Animal propagation and genomic survey of a genotype 1 isolate of Cryptosporidium parvum. Mol Biochem Parasitol 108, 187-197.

Xiao, L., Alderisio, K., Limor, J., Royer, M. \& Lal, A. A. (2000). Identification of species and sources of Cryptosporidium oocysts in storm waters with a small-subunit rRNA-based diagnostic and genotyping tool. Appl Environ Microbiol 66, 5492-5498.

Xiao, L., Bern, C., Limor, J., Sulaiman, I., Roberts, J., Checkley, W., Cabrera, L., Gilman, R. H. \& Lal, A. A. (2001). Identification of 5 types of Cryptosporidium parasites in children in Lima, Peru. J Infect Dis 183, 492-497.

Xiao, L., Fayer, R., Ryan, U. \& Upton, S. J. (2004). Cryptosporidium taxonomy: recent advances and implications for public health. Clin Microbiol Rev 17, 72-97. 